\title{
Experimental Work on Cold Starting Emission of CI Engine using Engine Waste Heat Energy
}

\author{
Mahendra Kumar Rath, Rashmi Ranjan Panda, Sanjay Patnaik
}

\begin{abstract}
In the present day, emission by internal combustion engines causes several problems like acid rain, depletion of ozone layer, and global warming for which it has become a prior concern. The hazards further increases during cold weather conditions. In this paper, emission analysis has been carried out using single cylinder, 4 stroke, direct injection and water cooled variable compression ratio diesel engine. A thermal energy storage device (TESD) containing phase changing material (PCM) has been designed and tested for storing the waste energy of cooling water from engine and reutilizing it for pre-heating. The working principle of TESD is based upon the principle of absorbing and rejecting heat during phase change of PCM material. The test condition is $15^{\circ} \mathrm{C}$ and $1 \mathrm{~atm}$ pressure at which, the experiments are carried out using TESD. A significant reduction in $\mathrm{CO}$ (23.72\%), HC (2.03\%) and smoke opacity (6.05\%) after 900secs and an increase in engine temperature upto $61^{\circ} \mathrm{C}$ after 840 secs of engine running is observed.

Keywords: Direct Injection, Emission, Karanja oil, Pre Heating, Variable compression ratio, Waste energy.
\end{abstract}

\section{INTRODUCTION}

The increasing concern regarding the uncertainty of energy availabilities in future draws attention towards various methodologies of utilizing renewable energies and energy conservation methods. A large portion of our power requirements are obtained using diesel engines. In diesel engine various problems arises during cold weather conditions such as higher fuel consumption, toxicity in emission and noticeable vibration and noise [1, 2]. Certain emission standards are maintained in order to keep the emission within acceptable range. Lots of energy is wasted in the form of exhaust gas and cooling water i.e. nearly twothird of the total input. It is difficult to conserve all the lost energy of the engine however, it can be minimized upto some extent. During cold start in the first 300secs, $60-80 \%$ of engine exhaust emission occurs [3, 4]. Several types of heat exchangers are used in order to extract energy, of which the most used are shell and tube types. For storage of energy and reduction in emission using heat exchangers, a phase changing material have been used

\section{Revised Manuscript Received on February 05, 2020.}

* Correspondence Author

Mahendra Kumar Rath*, Associate Professor, Dept. of Mechanical Engineering, Centurion University of Technology and Management, Bhubaneswar, Odisha, India.Email: mkrath@cutm.ac.in

Rashmi Ranjan Panda, Assistant Professor, Dept. of Mechanical Engineering, Centurion University of Technology and Management, Bhubaneswar, Odisha, India.Email: rashmi.panda@cutm.ac.in

Sanjay Patnaik, M.Tech Scholar, Dept. of Mechanical Engineering, Centurion University of Technology and Management, Bhubaneswar, Odisha, India. Email: sanjay_0675@rediffmail.com

(c) The Authors. Published by Blue Eyes Intelligence Engineering and Sciences Publication (BEIESP). This is an open access article under the CC BY-NC-ND license (http://creativecommons.org/licenses/by-nc-nd/4.0/)
An experiment has been conducted using paraffin as a phase changing material and they found that a total heat of $10-15 \%$ has been recovered [5]. PCM are used for several purposes such as cooling of building walls [6], as engine coolant [7], solar heating $[8,9]$ and in many internal combustion engines [10-13]. They used $\mathrm{Na}_{2} \mathrm{HPO}_{4} \cdot 12 \mathrm{H}_{2} \mathrm{O}$ (sodium phosphate dibasic dodecahydrate) as PCM in evaporator and pressure regulator (E\&PR) for vaporizing the LPG at liquid phase and to reduce $\mathrm{CO}$ and $\mathrm{HC}$ emissions in cold starting conditions. From the experiment, it was found that the E\&PR containing PCM stores heat energy for 13.5hrs and supplies it for 500secs which is sufficient time for the cooling liquid to achieve minimum working temperature. Also, CO and HC emissions were reduced by $28.71 \%$ and $17.32 \%$ respectively [14]. An experiment was carried for pre-heating gasoline engine using sodium sulphate decahydrate as PCM which is cheap and abundantly available. He found that an effective working temperature is achieved during cold starting condition. Due to pre-heating of engine, the $\mathrm{CO}$ and $\mathrm{HC}$ emissions were reduced to $64 \%$ and $15 \%$ respectively [15]. From the experimental investigation, it was reported that emission parameters like $\mathrm{CO}$ and $\mathrm{HC}$ decreases during engine preheating and air preheating mode using diesel fuel compared to cold weather emissions [16].

\section{EXPERIMENTAL METHOD}

\section{A. Phase change material selection}

Specific criteria such as low toxicity, high density, availability, high thermal conductivity at solid state, high heat of fusion, harmless to environment, non-flammable and low cost. Among several phase changing materials (PCM), Paraffin Wax is chosen for storage of energy and heating of engine as it is plentily available, non-reactive, has stable chemical properties, low cost, high heat of fusion, safe and recyclable. Paraffin has working temperature ranging from $58^{\circ} \mathrm{C}$ to $60^{\circ} \mathrm{C}$.

\section{B. Design of Thermal Energy Storage Device (TESD):}

In order to select a TESD for experimentation some specific characteristics are required such as minimum level of thermal losses, small in dimension, satisfying safety norms and should be environmental friendly. The principle of working of TESD is based on two factors i.e. absorbing and rejecting of latent heat by PCM. 


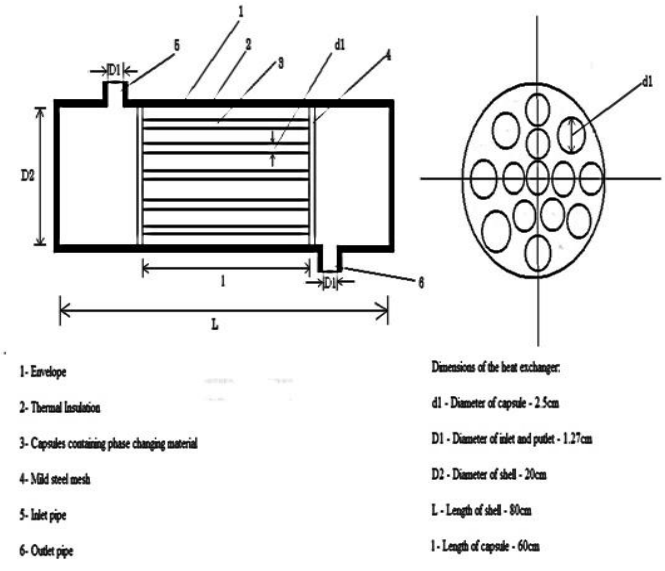

Fig. 1. Detailed dimensions of the developed thermal energy storage device

TESD consists of following parts such as envelope (1), thermal insulation (2), capsule containing PCM (3), mild steel mesh (4), inlet and outlet pipe $(5,6)$. The parameters considered for the capsule are $\mathrm{d} 1$ diameter of capsule, D1 inlet and outlet pipe diameter, D2 shell diameter, L length of shell and 1 length of capsule as shown in fig. 1. On both sides of the TESD, mild steel meshes are provided as the horizontal support for the copper pipes containing PCM. The length of the copper pipe is $600 \mathrm{~mm}$ and the diameter is $25 \mathrm{~mm}$. For effective heat storage and to minimize thermal losses, the TESD is thermally insulated with specific materials such as asbestos and glass wool.

\section{Location of TESD}

The cooling water in water jacket absorbs the heat energy from engine cylinder wall. By help of engine pump, cooling water at high temperature passes into TESD, where waste heat energy can be absorbed by PCM and get stored. This is the case during charging of PCM. During discharging process (engine is not running) in cold weather conditions, the water at atmospheric temperature is allowed to pass through the TESD in order to utilize the stored energy by PCM and to supply the same for engine pre-heating. TESD was placed in horizontal position and pump was set between TESD and engine. Inlet and outlet pipes of the TESD are connected with engine and pump by the help of specific valve arrangements to achieve the required amount of preheating.

\section{Experimental Setup and Procedure}

The experiments are carried out using a single cylinder, four stroke, variable compression ratio, water cooled and direct injection diesel engine of Kirloskar make with constant speed of 1500 r.p.m. The engine has a capacity of 661cc. The engine uses software of version 8.51 for operation and data collection. The experimental setup has a panel box which consists of air box, two fuel tanks for duel fuel test, manometer, fuel measuring unit, transmitters for air and fuel flow measurements, process indicator, engine indicator and a rotameter is provided for measuring the flow of cooling water. Experiments are carried out at compression ratio 18 and zero load or no- load condition. The engine has a specially designed tilting cylinder block arrangement for changing the compression ratio without the need to stop the engine. AVL 444 - 5 Gas Analyzer is used to measure CO and HC levels. AVL 437C smoke-meter is used to measure the smoke opacity of the exhaust gas. Several ' $K$ ' type thermocouples and temperature indicator are used to record the temperatures at different points. Inlet and outlet temperature of TESD at different un-identical points upon PCM (T8, T9, T10, T11, T12 and T13), exhaust gas temperature, temperatures of engine cylinder (T6) and engine head (T7). Few temperature readings are recorded by a personal computer with the help of some specific sensors provided in the setup. There are two phase of experimentation i.e. charging period (with engine in working condition) and discharging period (engine preheating is done). The experimental layout is provided in fig. 2.

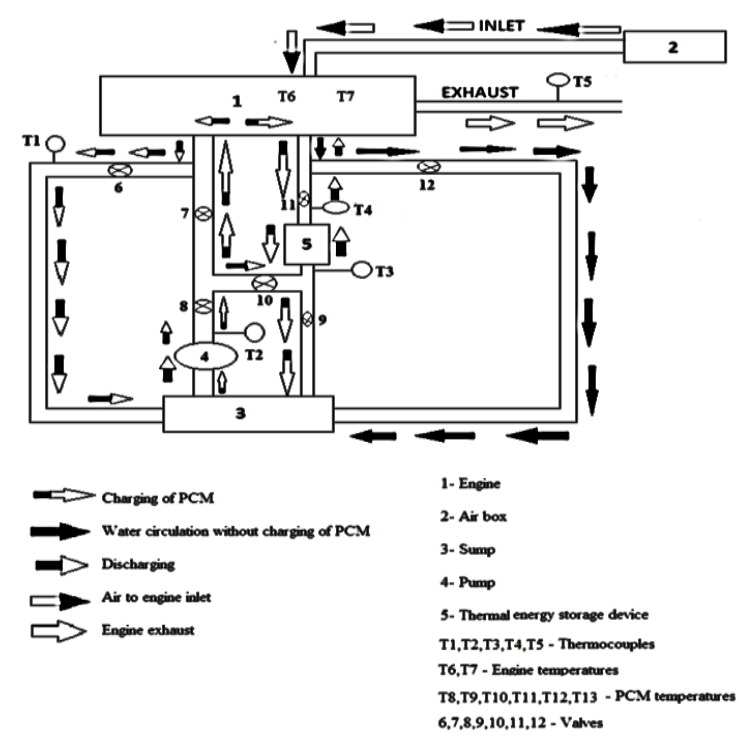

Fig. 2. Position of thermal energy storage device and location of thermocouples

In charging period, the engine is started at no load condition and was gradually increased to full load condition. The cooling water from the sump is directed towards the engine water jacket using valves 7, 8, 9 and 11 which remains open and allows the cooling water to pass through the TESD containing PCM. After specific time of completion of charging, high temperature cooling liquid from engine outlet is passed back to the sump. During the discharging period, pre-heating of engine is performed by passing water from sump through the TESD then it is supplied to the engine jacket during cold start condition. After discharging is over the cooling liquid is allowed to flow back to the sump using valve 6 . For maintaining the required flow rate of water an engine pump was provided. Required temperatures and the emission data were recorded during the experiment. The fuel used here for experimentation is diesel. 


\section{THEORETICAL ANALYSIS}

Amount of energy stored $\left(\mathrm{Q}_{\text {stored }}\right)$ was calculated by using following formula:

$\mathrm{Q}_{\text {stored }}=\mathrm{m}\left[\int_{T i}^{T 1} \operatorname{Cps}(T) d T+L+\int_{T 1}^{T f} \operatorname{Cpl}(T) d T\right]$

Where, $\mathrm{m}$ is the mass of material, Cps is the specific heat of material in solid phase, $\mathrm{Cpl}$ is the specific heat of material in liquid phase, $\mathrm{L}$ is latent heat of solid-liquid phase change, Ti initial temperature of solid state, T1 temperature of solidliquid phase change and $\mathrm{Tf}$ is final temperature of liquid state.

The amount of useful heat $\left(\mathrm{Q}_{\text {useful }}\right)$ necessary for preheating engine through temperature $\Delta T$ is calculated as

\section{$\mathrm{Q}_{\text {useful }}=\sum_{i} C_{i} m_{i} \Delta \mathrm{T}$}

Where $c_{i}$ and $m_{i}$ denote specific heat and mass of the engine components.

\section{RESULT AND DISCUSSION}

\section{A. Engine Temperature}

Fig. 3 shows the variation of engine temperature $\left({ }^{\circ} \mathrm{C}\right)$ according to time (sec) during discharging period. It is observed that engine temperature increases with respect to time. The increase in engine temperature may be due to the resulting effect of pre-heating of engine. Thermocouples T6 and $\mathrm{T} 7$ records the cylinder temperature and engine head temperature respectively. The engine temperature rises from $15^{\circ} \mathrm{C}$ ambient temperature to $33^{\circ} \mathrm{C}$ during cold weather condition after duration of 840secs in discharging period as the resulting effect of pre-heating.

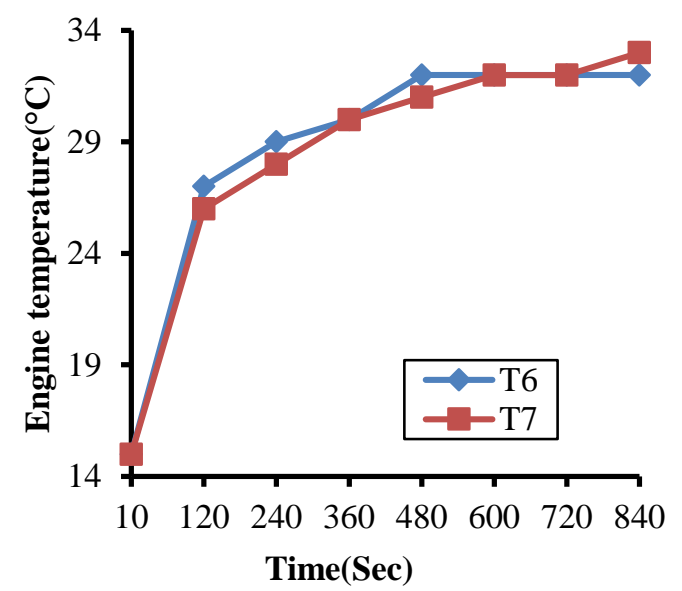

Fig. 3. Variation of engine temperature $\left({ }^{\circ} \mathrm{C}\right)$ according to time (sec) for CR-18

\section{B. PCM Charging Temperature}

The change in PCM charging temperature $\left({ }^{\circ} \mathrm{C}\right)$ with respect to time (sec) is shown in fig. 4. From the figure, it can be observed that the charging temperature of PCM increases according to time. The increase in temperature may be due to the effect of cooling water (at high temperature) from engine water jacket, which passes through TESD for absorption of waste heat energy by PCM. The stored thermal energy from water jacket is utilized during engine pre-heating. After 3000 secs of engine running time, the charging temperature of PCM increases from $15^{\circ} \mathrm{C}$ to $61^{\circ} \mathrm{C}$ in cold starting condition or warm up condition.

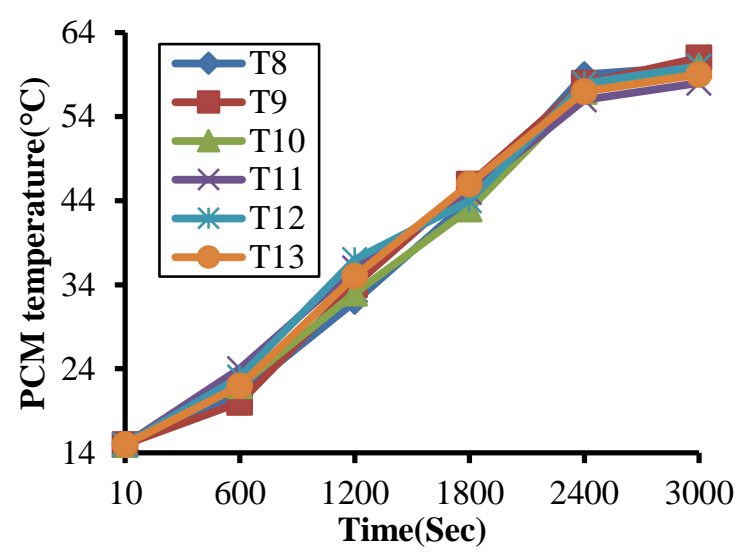

Fig. 4. Variation of PCM temperatures $\left({ }^{\circ} \mathrm{C}\right)$ according to time (sec) during charging period

\section{PCM Discharging Temperature}

The variation of discharging temperature of PCM $\left({ }^{\circ} \mathrm{C}\right)$ with respect to time (sec) is shown in fig. 5 . The figure shows a decrease in PCM temperature according to time. This may be due to the rejection of thermal energy by the PCM to the cooling water entering the engine for the purpose of pre-heating. The latent heat energy of phase changing material is stored for a period of $18 \mathrm{hrs}$ at $15^{\circ} \mathrm{C}$ ambient temperature with minimal thermal losses by the help of thermal insulation. After $18 \mathrm{hrs}$ of charging period, the discharging process was carried out and the engine remains in stop condition. After 3000secs of engine running, the discharging temperature decreases from $45^{\circ} \mathrm{C}$ to $29^{\circ} \mathrm{C}$ where the engine temperature becomes stable.

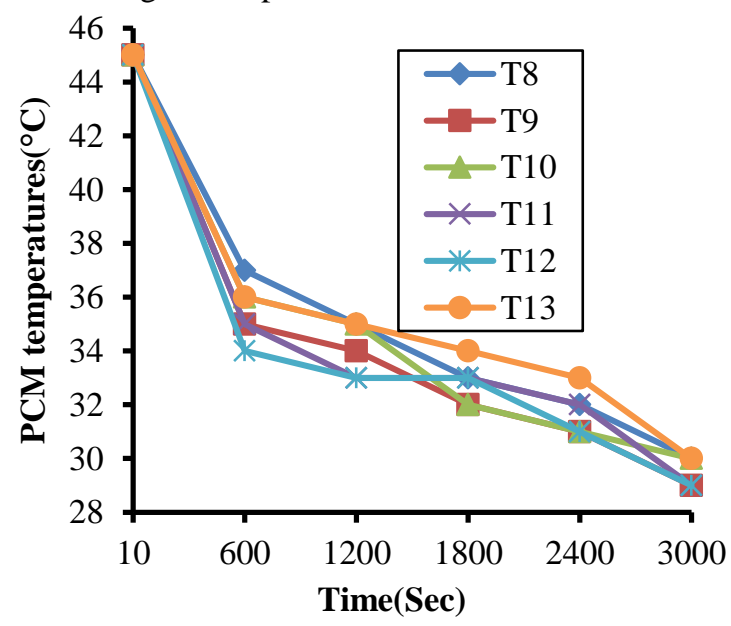

Fig. 5. Variation of PCM temperatures $\left({ }^{\circ} \mathrm{C}\right)$ according to time (sec) during discharging period

\section{Carbon Monoxide Emission}

Fig. 6 shows the variation of CO emission with respect to time at compression ratio 18. It is observed from the figure that $\mathrm{CO}$ emission is decreasing as the time of engine running is increasing. The decrease in emission may be due to the effect of engine pre-heating in comparison with normal emission. Engine pre-heating causes effective combustion thereby reducing the level of emission. During cold start, after 900secs of running engine with compression ratio 18 , normal CO emission is $0.0365 \%$ and after engine pre-heating gets reduced to $0.0295 \%$. 
The percentage of decrease in emission due to pre-heating was found to be $19.18 \%$.

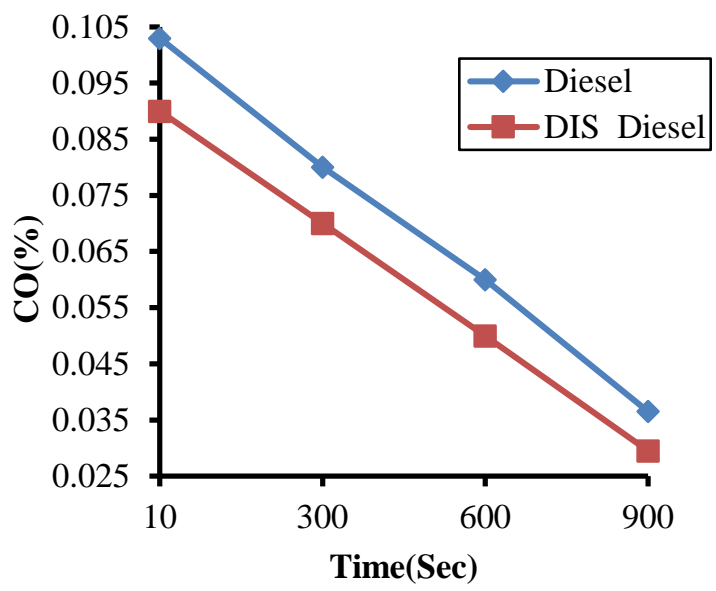

Fig. 6. Variation of CO (\%) according to time (sec) for CR-18

\section{E. Hydrocarbon Emission}

Fig. 7 shows the variation of $\mathrm{HC}$ emission with respect to time at a compression ratio of 18 for engine preheating and normal engine operation conditions. Hydro carbon emission was found to be reduced by increasing running duration of engine. The reason for this may be due to reduction in ignition delay for engine pre-heating resulting in effective combustion which enhances the reduction in the amount of partially burnt and unburnt fuel in exhaust causing HC emissions. In cold starting conditions after 900 secs of engine running at compression ratio 18 , the $\mathrm{HC}$ emission for normal condition is 24.08ppm and during pre-heating is 23.6ppm. The percentage of decrease in emission during pre-heating is $2.03 \%$ as compared to normal conditions.

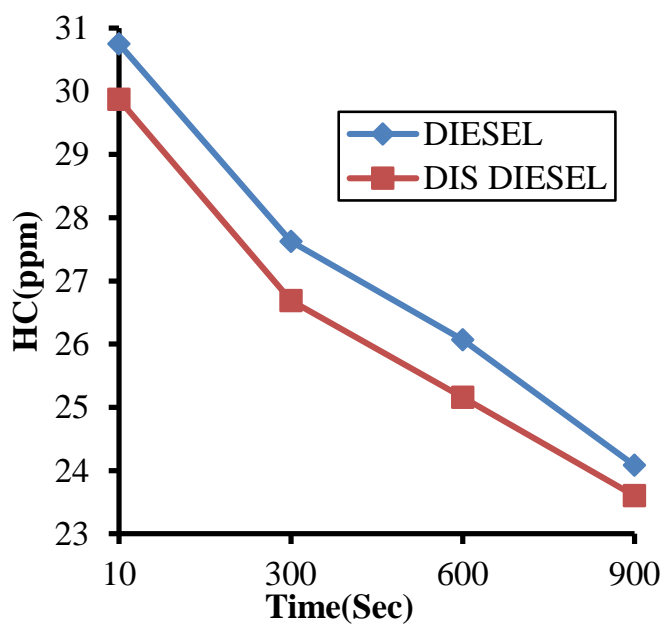

Fig. 7. HC (ppm) Vs time (sec) for CR-18

\section{F. Smoke Opacity}

The variation of smoke opacity according to time is represented in fig. 8 at compression ratio 18. It is observed from the figure that smoke opacity reduces with respect to time. This may be due to the effect of engine pre-heating which causes the fuel to become less viscous and better atomization of fuel occurs. Complete combustion of injected fuel occurs resulting in effective smoke reduction. After 900secs of engine running time, smoke opacity for normal condition is $21.88 \%$ and for pre-heating it gets reduced to $20.63 \%$. The percentage of reduction in smoke opacity during pre-heating condition is $6.05 \%$ as compared to normal smoke emission.

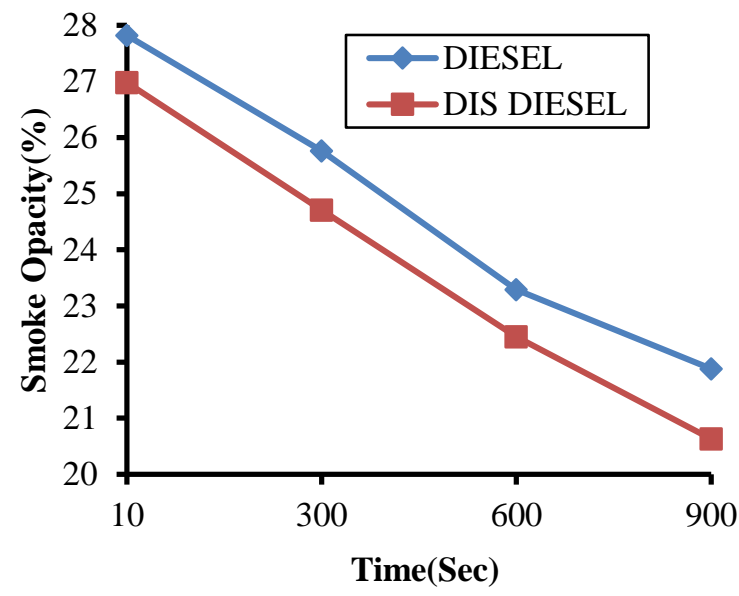

Fig. 8. Smoke opacity (\%) Vs time (sec) for CR-18

\section{CONCLUSION}

Experimental analysis have been carried out using VCR engine in compression ratio 18 and a thermal energy storage device (TESD) for pre-heating of engine at cold starting conditions. Paraffin wax was used as the phase changing material inside the TESD for the purpose of storing the heat energy from the cooling water coming out of the engine water jacket and utilizing it later during cold starting conditions for preheating the engine. The process of preheating is carried out using TESD at $15^{\circ} \mathrm{C}$ ambient temperature. The analysis of the results from the experimentation shows that this method is effective for reduction in emission during cold starting conditions and also it enhances the performance of the engine. The following conclusions can be drawn from the above observations:

* The temperature of engine increases during cold starting condition due to effect of pre-heating which improves the emissions characteristics. Preheating of engine causes a rise in temperature of the engine from $15^{\circ} \mathrm{C}$ to $33^{\circ} \mathrm{C}$ after 840 secs of engine running in cold weather conditions or warm conditions.

* The charging of TESD has been successfully done. The temperature of PCM during the charging mode increases from $15^{\circ} \mathrm{C}$ to $61^{\circ} \mathrm{C}$ after 3000secs of engine running time. It stores the energy for a period of $18 \mathrm{hrs}$.

* After 18hrs of charging period, discharging process is carried upon. The heat energy stored in the PCM is utilized to preheat the engine. The temperature of PCM inside the TESD decreases from $45^{\circ} \mathrm{C}$ to $29^{\circ} \mathrm{C}$ in 3000 secs of engine running time as the resulting effect of energy rejection to the cooling water which in turn preheats the engine for warm startup or cold starting conditions. 
* CO emission found to be reduced in pre-heating mode as compared normal mode. After 900secs of running of engine with compression ratio 18 , $\mathrm{CO}$ emission is $0.0365 \%$ in normal conditions and $0.0295 \%$ during engine pre-heating. The percentage of decrease in emission is $23.72 \%$ as resulting effect of pre-heating.

* HC emission reduces after pre-heating of engine has been done. HC emission at 900 secs of engine running in normal mode is $24.08 \mathrm{ppm}$ and during engine preheating is 23.6ppm. The percentage of decrease in emission during pre-heating is $2.03 \%$ as compared to normal conditions.

* Smoke opacity reduces with time. After 900secs of engine running smoke opacity for normal operating condition is $21.88 \%$ and for pre-heating is $20.63 \%$. The percentage of reduction in smoke opacity is $6.05 \%$ as compared to normal smoke emission as a resulting effect of pre-heating condition.

Hence it is concluded from this experimental work that the thermal energy storage device containing paraffin wax is a cheap and abundantly available phase changing material and can be used for storing the waste thermal energy from the engine and reutilize it for preheating of engine under cold starting conditions to efficiently reduces the exhaust emissions.

\section{REFERENCES}

1. Zahdeh, A., Henein, N. and Bryzik, W., "Diesel cold starting: actua cycle analysis under border-line conditions", SAE Technical Paper, 900441, (1990).

2. Jorgensen, S.W., "Compression temperature in a cold cranking engine”, SAE Technical Paper, 880045, (1988).

3. Shayler, P.J. and Belton, C., "In-cylinder fuel behaviour and exhaust emissions during the cold operation of a spark ignition engine", Automobile Eng., Vol. 213, No. 2, (1998), 161-173.

4. Seokhwan, L. and Choongsik, B.," The application of an exhaust heat exchanger to protect the catalyst and improve the fuel economy in a spark-ignition engine", Automobile Eng., Vol. 221, No. 5, (2007), 621628.

5. Pandiyarajan, V., Pandian, M.C., Malan, E., Velraj, R. and Seeniraj, R. V., "Experimental investigation on heat recovery from diesel engine exhaust using finned shell and tube heat exchanger and thermal storage system", Applied Energy, Vol. 88, No. 1, (2011), 77-87.

6. Tyagia, V.V., Buddhib, D., Kotharic Richa and Tyagid, S.K., "Phase change material (PCM) based thermal management system for cool energy storage application in building: An experimental study", Energy and Buildings, Vol. 51, (2012), 248-254.

7. Malatidis, N., "Warmespeicher Insbesondere Latentwarmespeicher für Kraftfahrzeuge", Patent DE 3990275 C 1, (1988).

8. Saman, W., Bruno, F. and Halawa E., "Thermal performance of PCM thermal storage unit for a roof integrated solar heating system", Solar Energy, Vol. 78, No. 2, (2005), 341-349.

9. Shukla, A., Buddhi, D and Sawhney, R.L., "Solar water heaters with phase change material thermal energy storage medium: a review", Renewable and Sustainable Energy reviews, Vol. 13, No. 8, (2009), 2119-2125.

10. Karthik, R.,West, D. H. and Balakotaiah, V., "Optimal design of catalytic converters for minimizing, cold-start emissions", Catal Today, Vol. 98, No. 3, (2004), 357-373.

11. D.J. Boam, "Energy audit on a two-litre saloon car driving an ECE 15 from a cold start", Automobile Eng., Vol. 200, No. 14, (1986), 66-67.

12. O. Schatz, "Cold-start improvements with latent heat store", Automotive Eng., (1992), 58-61.

13. Darkwa, K., O’Callaghan, P.W., “Green transport technology (GTT): analytical studies of a thermochemical store for minimising energy consumption and air pollution from automobile engines", Appl. Therm. Eng., Vol. 17, No. 7, (1997), 603-614.

14. Gumus, M. and Ugurlu, A., "Application of phase change materials to pre-heating of evaporator and pressure regulator of a gaseous sequential injection system”, Applied Energy, Vol. 88, No. 12, (2011), 4803-4810.
15. Gumus, M., "Reducing cold-start emission from internal combustion engines by means of thermal energy storage system", Applied Thermal Engineering, Vol. 29, No. 4, (2009), 652-660.

16. Rath,M.K., S.K. Acharya,S.K., "Emission analysis of CI engine during cold weather conditions using preheated air and engine using waste energy and phase change material", International Journal of Ambien Energy, Vol. 39, No. 3, (2018), 278-284.

\section{AUTHORS PROFILE}

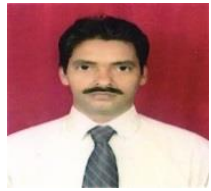

Dr. Mahendra Kumar Rath. is an Associate Professor, Dept. of Mechanical Engineering, Centurion University of Technology and Management, Bhubaneswar, Odisha, India. He had completed his Doctoral degree in 2015 from S'O'A University, Bhubaneswar, Odisha, India. He had more than nine years of research experience in different fields of engineering and had six publications in different SCOPUS indexed journals. His areas of interests are Biofuel, Renewable energy, Internal combustion Engines, Refrigeration and Air conditioning and Alternative Fuel.

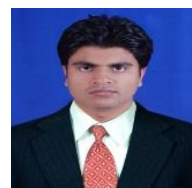

Prof. Rashmi Ranjan Panda is an Assistant Professor, Dept. of Mechanical Engineering, Centurion University of Technology and Management, Bhubaneswar, Odisha, India. He had completed his M.Tech degree in 2014 from Centurion University with gold medal Bhubaneswar, Odisha, India. He had more than four years of research experience in different fields of engineering and had 10 publications in different UGC indexed journals. His areas of interests are Manufacturing, Additive manufacturing, Renewable energy and Internal combustion Engines.

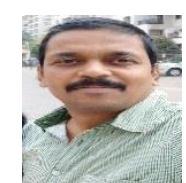

Mr. Sanjay Patnaik, Research Scholar, Dept. of Mechanical Engineering, Centurion University of Technology and Management, Bhubaneswar, Odisha, India. He had completed his B.E. in Mechanical Engineering from D. Y. Patil Engineering College, Shivaji University, Kolhapur. His research area is optimization of profit by minimizing manpower in Industry sector. 